\title{
Effectiveness of deep cervical fascial manipulation and yoga postures on pain, function, and oculomotor control in patients with mechanical neck pain: study protocol of a pragmatic, parallel-group, randomized, controlled trial
}

Prabu Raja $\mathrm{G}^{1} \mathbb{D}$, Shyamasunder Bhat N² ${ }^{*}$, César Fernández-de-las-Peñas ${ }^{3}$, Ranganath Gangavelli ${ }^{4}$, Fiddy Davis ${ }^{5}$, Ravi Shankar ${ }^{6}$ and Anupama Prabhu ${ }^{4}$

\begin{abstract}
Introduction: Mechanical neck pain (MNP) is a commonly occurring musculoskeletal condition that is usually managed using electrical modalities, joint mobilization techniques, and therapeutic exercises, but has limited evidence of their efficacy. Pathology (densification) of the deep cervical fascia that occurs due to the increased viscosity of hyaluronic acid (HA) may induce neck pain and associated painful symptoms of the upper quarter region. Fascial manipulation (FM) and yoga poses are considered to reduce the thixotropy of the ground substances of the deep fascia and improve muscle function. The purpose of this study is to investigate the effect of FM and sequential yoga poses (SYP) when compared to the usual care on pain, function, and oculomotor control in MNP.

Methods: This FaCe-Man trial will recruit 160 patients with subacute and chronic mechanical neck pain diagnosed using predefined criteria. Participants will be randomized to either the intervention group or the usual care group, using a random allocation ratio of 1:1. Patients in the intervention group will receive FM (4 sessions in 4 weeks) and SYP (12 weeks) whereas the standard care group will receive cervical mobilization/ thoracic manipulation (4 sessions in 4 weeks) and therapeutic exercises (12 weeks). The primary outcome is the change in the numeric pain rating scale (NPRS). The secondary outcomes include changes in the patient-specific functional scale and oculomotor control, myofascial stiffness, fear-avoidance behavior questionnaire, and elbow extension range of motion during neurodynamics test 1.
\end{abstract}

\footnotetext{
* Correspondence:

${ }^{2}$ Department of Orthopedics, Kasturba Medical College, Manipal Academy of Higher Education, Manipal, India

Full list of author information is available at the end of the article
}

(C) The Author(s). 2021 Open Access This article is licensed under a Creative Commons Attribution 4.0 International License, which permits use, sharing, adaptation, distribution and reproduction in any medium or format, as long as you give appropriate credit to the original author(s) and the source, provide a link to the Creative Commons licence, and indicate if changes were made. The images or other third party material in this article are included in the article's Creative Commons licence, unless indicated otherwise in a credit line to the material. If material is not included in the article's Creative Commons licence and your intended use is not permitted by statutory regulation or exceeds the permitted use, you will need to obtain permission directly from the copyright holder. To view a copy of this licence, visit http://creativecommons.org/licenses/by/4.0/. The Creative Commons Public Domain Dedication waiver (http://creativecommons.org/publicdomain/zero/1.0/) applies to the data made available in this article, unless otherwise stated in a credit line to the data. 
Discussion: If found effective, FM along with SYP investigated in this trial can be considered as a treatment strategy in the management of mechanical neck pain. Considering the magnitude of the problem, and the pragmatic and patient-centered approach to be followed, it is worth investigating this trial.

Trial registration: ClinicalTrials.gov CTRI/2020/01/022934. Registered on January 24, 2020 with ctri.nic.in. Clinical Trials Registry - India.

Keywords: Cervical pain, Musculoskeletal manipulation, Active stretching, Soft tissue therapy, Eye movements, Connective tissue

\section{Background}

Mechanical neck pain (MNP) is a commonly occurring musculoskeletal condition in the adult population [1]. MNP is defined as non-specific pain in the area of the cervicothoracic junction exacerbated by neck movements $[2,3]$. The prevalence of MNP ranges from 5.9 to 38.7\% [3]. Almost half of the MNP patients may develop chronic symptoms, contributing significantly to global disability and substantial societal burden [1,3]. A study that investigated the factors associated with neck and shoulder pain in young adults has reported that increased screen-based activities (prolonged use of computers and mobiles) without any physical activity resulted in a higher prevalence of neck pain among adults [4].

MNP may be associated with temporomandibular pain, oculomotor dysfunctions, headaches, non-otogenic otalgia, and non-odontogenic toothache [5]. Because of the multifactorial presentation of painful symptoms, MNP is often termed as non-specific neck pain and is managed conservatively using electrical modalities, joint mobilization techniques, and therapeutic exercises [3].

A systematic review has shown multiple cervical manipulation sessions may provide better pain relief and functional improvement than medications. The authors have also reported that cervical manipulation and mobilisation present similar results for all outcomes, including pain, function, and patient satisfaction [6]. Considering the association between decreased thoracic mobility and cervical pain as well as the higher risk of cervical manipulation complications, thoracic manipulation is preferred [7]. Also, a review has reported the effectiveness of therapeutic exercises in neck pain patients is uncertain without high-quality evidence [8]. Moreover, the clinical prediction rules pertinent to the conventional management of neck pain in adults are at the preliminary stage which mandates the need for their validation [9].

The mechanosensitive neural tissue is considered a primary feature in cervicobrachial pain syndrome with pain in the upper quarter region (UQR) [10, 11]. Nevertheless, Gangavelli et al. reported that only $19.9 \%$ of cases are of neurogenic origin [12]. In addition, Butler had proposed that not all "positive tension tests" indicate adverse neurodynamics, and the neurodynamics tests are not specific enough to indicate abnormal neural mobility [13-15]. In patients with positive neurodynamics tests, there can be diverse problems that are not related to "neural tension" that may create a painful response [14]. A systematic review of anatomical studies has reported that deep cervical fascia (DCF) links the muscles of the $\mathrm{UQR}$, thus forming the in-series myofascial continuity, which may induce nociceptive pain in cervicobrachial pain $[16,17]$.

Studies have shown the existence of myofascial expansions, where the DF connects the different muscles of the UQR $[18,19]$. The deep cervical fascia (DCF) at the neck has myofascial continuity proximally and distally, forming a myofascial continuum (MC) of the upper quarter. The DCF and its MC that links the head, neck, and upper extremity are illustrated in Fig. 1 [19, 20]. The presence of nociceptors in such connective tissues may convey nociceptive signals directly. Besides, the proprioceptors may change to nociceptors, thus transforming the mechanical stimuli into pain signals. Studies have reported that changes in the hyaluronan of the connective tissues may alter the viscoelasticity of the myofascia resulting in the activation of nociceptors. Thus, dysfunctions of the DCF may be the causative factor in non-specific pain and other symptoms of the eye, head, neck, and arm associated with MNP [17, 21].

Oculomotor dysfunctions associated with MNP are the sensorimotor dysfunctions of the oculomotor system characterized by pursuit, saccade, and convergence deficiencies [22, 23]. EMG studies have revealed an altered activation of the temporomandibular joint and neck muscles in patients with visual defects [23, 24]. Studies have shown an increase in the cervico-ocular reflex (COR) [23] and ocular symptoms such as visual stress, lachrymation in patients with non-specific neck pain attributing it to the impaired receptors at the facets and the deep muscles of the cervical spine [25-27].

The fascia's inability to extend and accommodate the craniocervical musculature tension is hypothesized to have occurred due to the modification of the DCF in chronic MNP. Restoring the physiological elasticity of 


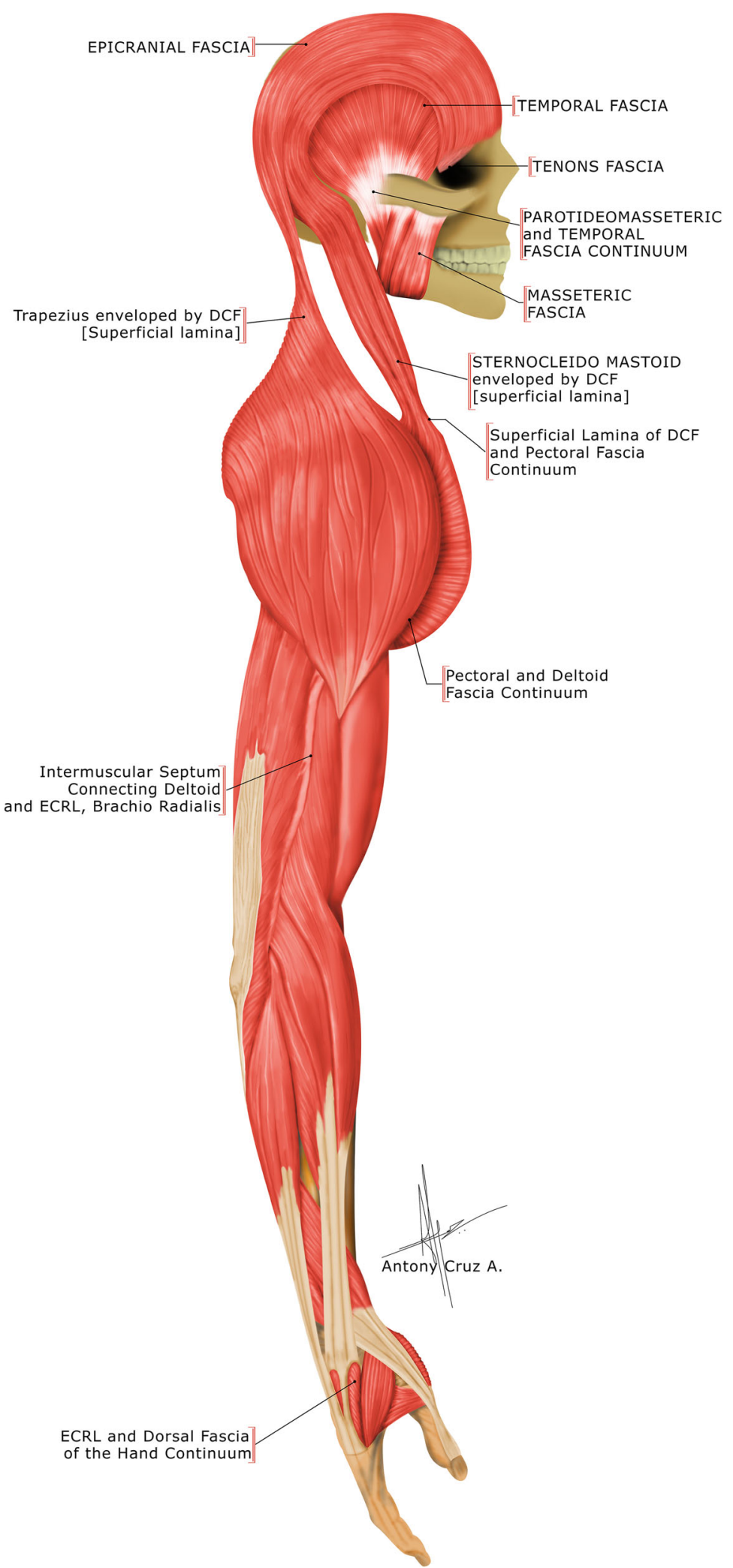

Fig. 1 Deep Cervical Fascia and its Continuum (৫ Antony Cruz \& Prabu Raja) 
the DCF by FM may result in appropriate afferent inputs from the receptors present in the neck muscles that elicit COR, leading to improved oculomotor control.

The increased viscosity of hyaluronan leads to the formation of adhesions and the generation of tensional forces. The adhesions alter the activation of mechanoreceptors, leads to the non-physiologic movement of the joints, resulting in pain and dysfunctions [28-31].

Fascial manipulation (FM) is hypothesized to restore the restricted movement of collagen and elastin fibers within the ground substance. The manipulation of the densified center of coordination (CC) and center of fusion (CF) points might improve the flexibility of the myofascial structures, thereby improving the fascial mobility and the associated symptoms [17, 28, 31]. Besides FM, sequential yoga poses (SYP) also focus on the myofascial lines. It restores fluid flow, decreasing the thixotropy in the ground substances, leading to the muscles' effective and efficient functioning [32-34].

Patient-reported outcome measures (PROM) such as the numeric pain rating scale (NPRS) and patientspecific functional scale (PSFS) are used in assessing pain and function, respectively [35].

The presentation of various symptoms of the upper quarter with MNP leads to an extensive treatment without any significant treatment effect. Concomitant occurrence of symptoms such as neck pain, headache, and visual dysfunctions may occur due to the impairment in the anatomical fascial connections between the deep cervical fascia (DCF), epicranial fascia, and the tenon's fascia. A well-designed pragmatic study incorporating manipulation of the DCF, and its continuum in MNP is needed. Thus, the FaCe-Man trial aims to study the efficacy of FM of DCF and SYP when compared to usual care (cervical mobilization $(\mathrm{CM})$, thoracic manipulation (TM), cervicothoracic manipulation (CTM), and homebased therapeutic exercises (TE) on pain, function, and oculomotor control in patients with sub-acute and chronic MNP.

\section{Objectives}

\section{Primary research question}

Are fascia directed treatment approaches, including 4 sessions of FM in 4 weeks and 3 months of home-based SYP (5 days/week) better than usual care, including 4 sessions of CM, TM, CTM, and 3 months of homebased TE (5 days/week) for improving pain, function, and oculomotor control in patients with subacute and chronic mechanical neck pain?

\section{Primary objective}

The primary objective of this study is to determine the effectiveness of fascia directed approach that includes FM (4 sessions in 4 weeks) and 3 months of home-based
SYP (5 days/week) as compared to 4 sessions of CM, TM, CTM, and 3 months of home-based TE (5 days/ week) on pain using numerical pain rating scale (NPRS).

\section{Primary research hypothesis}

The hypothesis of this study is there will be a significant improvement in MNP patients who undergo fasciadirected treatment approaches (FM and SYP) in reducing pain.

\section{Secondary objectives}

To study the effectiveness of fascia directed treatment approaches (FM \& SYP), in comparison to usual care on function, oculomotor control, elbow extension range of motion (ROM) during ULNT1, viscoelastic properties (tone, stiffness, elasticity) of myofascia, and patientreported fear avoidance behavior.

\section{Trial design}

The FaCe-Man trial is a pragmatic, outcome assessorblinded, randomized, controlled superiority trial with two parallel groups. Randomization will be implemented as stratified (age-based) block randomization with a 1:1 allocation ratio. The trial report is based on the SPIRIT guidelines and checklist-2013 [36] (Additional file 1) and TIDieR guidelines for intervention description and replication [37, 38] (Additional files 2 and 3).

\section{Methods}

Methods: participants, interventions, and outcomes Study duration

This study period is planned from October 8, 2019, to October 7, 2023.

\section{Study setting}

Outpatient clinic - Department of Orthopedics at Kasturba Hospitals (recruitment), Center for Sports Science, Medicine, and Research (Interventions and Outcome Measures) and Outpatient Clinic - Department of Speech and Hearing (Outcome Measures), Manipal Academy of Higher Education, Manipal, Karnataka, India.

\section{Study flow}

The study flow is outlined in Fig. 2.

\section{Eligibility criteria}

\section{Inclusion criteria}

- Participants: Individuals with sub-acute or chronic MNP for more than 3 weeks.

- Age group: Between 18 and 45 years. 


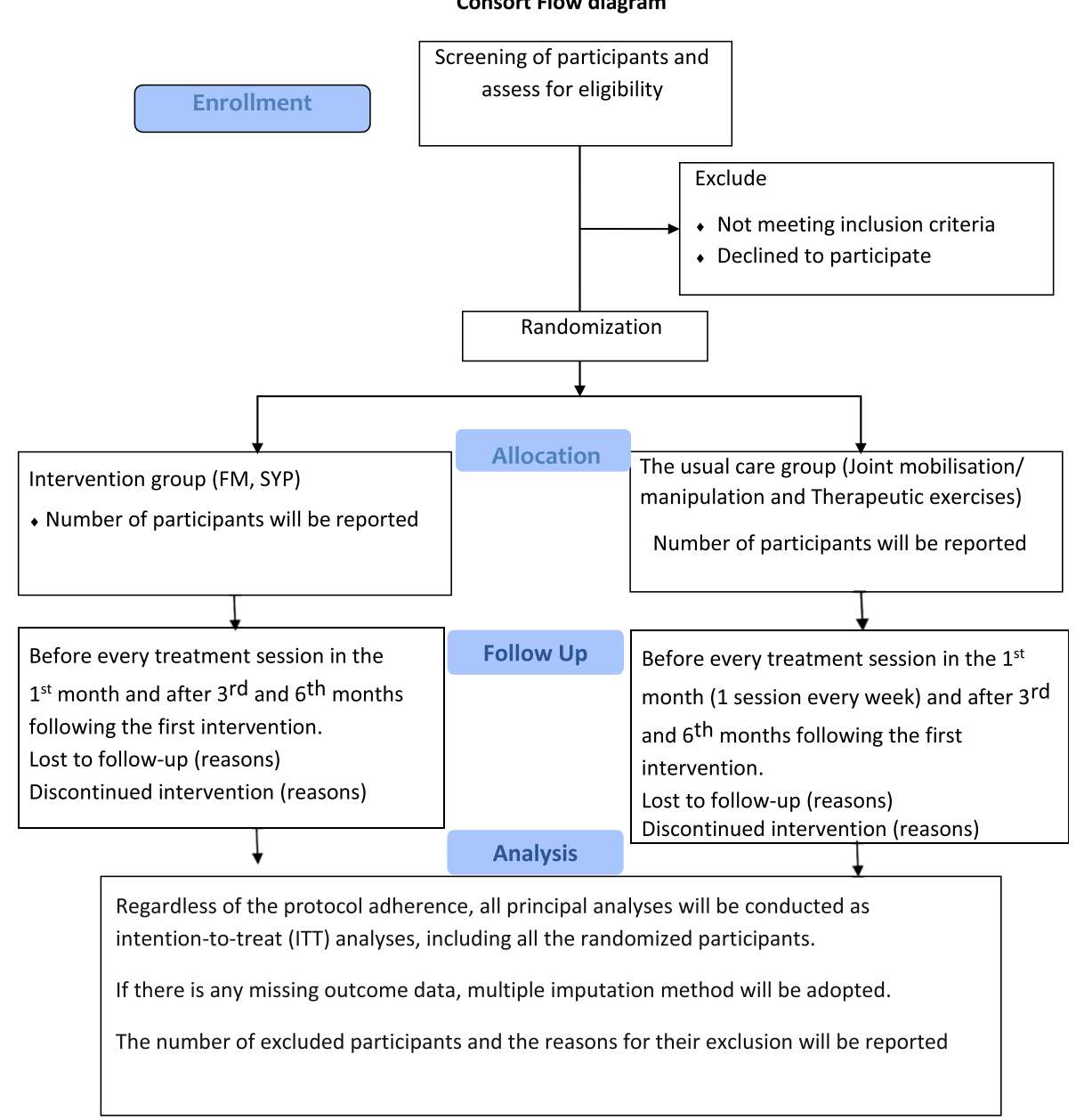

Fig. 2 Consort Flow diagram

Exclusion criteria Patients diagnosed with any bony lesions, inflammatory diseases, skin infections, vestibular balance disorders, sensory and motor deficits of the $\mathrm{UQR}$, and the history of surgery/trauma to the UQR in the last year or presenting with conditions that are considered as red flags for manual therapy.

\section{Interventions}

In this study, usual care includes therapeutic exercises, cervical mobilization $(\mathrm{CM})$, and thoracic manipulation (TM). Joint mobilization/manipulation will be provided during day 1 and the next three treatment sessions with a 1-week interval between the sessions. Patients in the intervention group will receive FM and instructions regarding home-based SYP. Instructions regarding the home-based therapeutic exercises for the usual care group and sequential yoga poses for the interventional group will be provided during the first treatment session. Regular monitoring of the exercises and SYP will be done during different treatment and follow-up sessions.

\section{Usual care group (CM and TM)}

Manipulation involves unidirectional thrust movement, whereas mobilization includes smooth oscillatory movements. Large amplitude oscillatory movements and small amplitude at the end range will be used for treating pain and stiffness, respectively. When treating muscle spasm, the rhythm is mainly a sustained position at a point where further movement is restricted by muscle spasm for $1 \mathrm{~min}$ in the order of $10-20 \mathrm{~s}$. This sustained progressive position is interspersed with oscillatory movements [39-45].

Therapeutic exercises:

Home-based exercises will be taught, including upper cervical spine mobility and stretching of neck musculature to improve mobility and flexibility. Following this, reeducation of the craniocervical flexion (CCF) and progressive training of deep neck flexors and extensors, as well as axio-scapular muscles, will be taught. The details of the usual care are shown in Additional file 2: TIDieR Control group (Usual care group) [37, 38]. The patient's home- 
based exercises are illustrated in Additional file 4: Therapeutic exercises - Information leaflet [3].

\section{Intervention group (FM and SYP)}

The intervention group will receive fascial manipulation and sequential yoga poses.

Fascial manipulation Fascial manipulation (FM) targets the densified points located on the deep muscular fascia termed as the center of coordination (CC) and the center of fusion (CF), which are located on the ligaments, retinacula, and intermuscular septa $[17,19,28]$. The densification may occur at the $\mathrm{CC}$ and $\mathrm{CF}$ points and are formed due to repetitive abnormal mechanical stresses such as abnormal neck postures. Palpation and movement verifications of the CCs and CFs of the most dysfunctional MFU will be done before selecting the points to be treated for each treatment session. A study on the reliability of movement and palpation assessments in patients with coxarthrosis using the FM method has demonstrated high reliability even if performed by novice FM practitioners [46]. After the identification of a densified center of coordination (CCs) and center of fusion (CFs) by palpation, FM is done by deep friction massage using elbows or knuckles for 5-8 min at each densified CCs and CFs $[45,47,48]$. FM is considered to stimulate these intrafascial mechanoreceptors (paciniform corpuscles, ruffini endings, and interstitial receptors) resulting in altered regulation of motor units thus changing the tissue metabolism and fluid dynamics $[19,48]$.

Sequential yoga poses Sequential yoga poses focusing on the myofascial continuum of the UQR will be done in the following sequences: triangle pose, extended side angle pose, seated eagle pose, cow face pose, child pose, reverse prayer pose, camel pose, bow pose, and child pose. Each posture will be held for a period of 5 breath cycles, which will be progressed by increasing the number of breathes during these asanas [32-34]. The interventions' details are given in Additional file 3: TIDieR Intervention group [37, 38]. The patient's home-based yoga poses are illustrated in Additional file 5: Yoga poses- Information leaflet [32-34].

\section{Intervention adherence}

Steadfast adherence to exercise-based interventions enhances the effectiveness of the interventions in rehabilitation. Studies have shown that robust exercise adherence may improve neck and back pain patients [49, 50]. The patients will be explained the significance of adhering to study guidelines of home-based rehabilitation exercises and the importance of proper form and exercise execution. The patients will also be advised to contact the investigator on events of any acute flare-up of symptoms.

Reminders via e-mail at regular intervals and Google forms will be sent. Participants will give feedback regarding the intensity, frequency, and duration of their exercise training and the difficulties in performing exercises, improving the adherence and ensuring their participation in the study. These data will be collected once in 2 weeks during the unsupervised exercises following four treatment sessions until the end of 3 months. The investigator will provide leaflets (Additional files 4 and 5) depicting the entire exercise regimen and daily logbook, which will act as reminders if the participants do not have access to the e-mails.

\section{Interventions-concomitant care}

The concomitant use of NSAIDs, muscle relaxants, and analgesics will be based on the physician's recommendation and at patients' discretion. The medications used will be recorded.

\section{Outcomes \\ Primary outcome measure}

- Numeric pain rating scale (NPRS).

Numeric pain rating scale The NPRS is a valid and reliable PROM used for MNP patients. The NPRS has a moderate reliability (ICC $=0.67$; $[0.27$ to 0.84$]$ ] [51]. Participants will indicate the intensity of neck pain in the past week. A reduction of 1 point in the NPRS was represented as the minimal clinical important difference (MCID) in patients with chronic musculoskeletal pain [52].

Baseline values will be collected from participants before the first treatment session. Also, the patient's expected improvement in the NPRS scale following interventions will be assessed. This primary outcome data will be further collected during the $2 \mathrm{nd}$, 3rd, and 4th treatment sessions and the 3rd month and 6th month following the first treatment session. The principal analysis will be performed for changes from baseline to 3- and 6-month follow-up and between the treatment sessions. It will be reported as the difference in the change in the mean between the groups. During analysis, a change score of two in the NPRS scale will be considered as MCID as this score is associated with "much better" improvement [52].

\section{Secondary outcome measures}

- Patient-specific functional scale (PSFS)

- Oculomotor control tests 
1. Smooth pursuit neck torsion (SPNT) test, saccades using videonystagmography

2. Near point convergence (NPC) test using RAF ruler

- Fear-avoidance belief questionnaire-physical activity (FABQ-PA)

- Myofascial stiffness using myoton-pro

- Elbow extension ROM during upper limb neurodynamics test 1 (ULNT1) using a goniometer

Patient-specific functional scale The PSFS quantifies the activity limitation in patients where the three most challenging and painful activities will be identified. The total score is the summation of all the activity scores divided by the total number of activities. The minimum detectable change (MDC) for an average rating is 2 points, and the MDC for a single activity score is 3 points [53]. Baseline values will be collected from participants before the first treatment session. Also, the patient's expected improvement in the PSFS following interventions will be assessed.

The primary analysis will be done for changes from baseline to the last treatment session and 3rd- and 6thmonth follow-ups and will be reported as the change in means between the groups.

\section{Oculomotor control tests}

Smooth pursuit neck torsion test The smooth pursuit neck torsion (SPNT) test assesses the smooth pursuit eye movements with a torsioned neck using videonystagmography (VNG) [54]. In this test, participants will be instructed to follow the target with the eyes without blinking as well as keeping the head still. Initially, smooth pursuit measurement will be performed with the neck and trunk in a neutral position followed by the torsioned position of the trunk to $45^{\circ}$ by rotating the trunk on the one side. The same procedure will be repeated, and measurements will be done by rotating the trunk on the opposite side $[54,55]$. The SPNT test parameter is the difference between the average gain in the neutral and torsioned positions $[25-27,56]$.

Saccades Saccades will be measured using VNG, which are rapid voluntary eye movements primarily directed towards stationary targets. In saccades, both eyes move simultaneously between two or more phases of fixation in the same direction. The parameters to be measured in saccades include peak velocity, measured in degrees/second, and latency in milliseconds $[25,26,54]$.

Near point convergence test NPC will be measured using an RAF ruler to identify the presence of any convergence insufficiency. Convergence insufficiency (CI) measured by near point convergence (NPC) may be a feature in MNP, thus measuring NPC with neck torsion may differentiate the cervical cause of CI. Giffard et al. have investigated the repeatability and reliability of NPC measurements in neutral and torsion position between the neck pain patients and controls using a Royal Airforce (RAF) ruler. A significant NPC torsion difference was demonstrated in participants with NP compared to controls $(P=0.01)$. No significant differences were seen for NPC values in neutral $(P=0.73)$. High inter-rater reliability (ICC $=0.95)$ and repeatability $(\mathrm{ICC}=0.84)$ was obtained [57].

\section{Fear Avoidance Beliefs Questionnaire (FABQ)}

The fear-avoidance model (FAM) describes chronic pain development as a psychological process [58]. Although fear-avoidance beliefs (FAB) is considered a key variable in predicting, chronic low back pain (CLBP) FABQ was associated with pain and disability in patients with MNP in increasing order of fear-avoidance beliefs (FAB). FABQ includes a four-item scale, which measures the FAB about physical activity (FABQ-PA), and a sevenitem scale, which measures the FAB about work (FABQW). The questions of the FABQ refer to "neck pain" instead of low back pain to address the participants with MNP [59]. Higher scores in the FABQ indicate greater levels of fear-avoidance beliefs. Although the association between $F A B$, pain, and disability in neck pain patients is weaker than in the LBP patients, studies have shown no significant difference in FAB between patients with neck and low back pain. Authors have shown that both FABQ work-related subscales have a substantial relationship with returning to work capability in patients with MNP [59, 60]. FABQ-PA scores include a total score and can be considered as an elevated score when it is 15 or above [58]. Principal analysis will be conducted for changes from baseline to the 3rd- and 6th-month follow-ups and will be reported as the change in the mean between groups. Lee et al. have demonstrated a very good content validity and test-retest reliability of FABQ questionnaire $(\mathrm{ICC}=0.81) /($ Cronbach's alpha coefficient $=0.90)$ [61].

\section{Myofascial stiffness}

The viscoelastic properties include elasticity (log decrement), stiffness $(\mathrm{N} / \mathrm{m})$, and tone $(\mathrm{Hz})$. These mechanical properties will be measured by using Myotonpro on the following muscles: masseter, temporalis, sternocleidomastoid, upper Trapezius, biceps brachii, infraspinatus, and teres minor. Myoton Pro induces oscillation on the skin surface, thus helps in determining the viscoelastic properties of the soft tissues of UQR [62,63]. The primary analysis will be conducted for changes from baseline to the final treatment sessions and 3rd-month 
follow-up. The results will be reported as the change in the means between groups.

\section{Elbow extension ROM during upper limb neurodynamics test}

The mechanosensitivity of the upper limb neural structures may occur due to the nerves' impaired mobility with their adjacent mechanical interface. The elbow extension ROM (EEROM) is the point in the elbow extension range while performing ULNT1, where the subject experiences pain or discomfort. This degree of elbow flexion will be measured using a standard goniometer $[13,64]$. The analysis will be performed for changes from baseline to 3and 6-month follow-up and between the treatment sessions. The results will be reported as the difference in the change in the mean between the groups.

\section{Participant's timeline}

The schedule of enrolment, interventions, and assessments of the participants are outlined in SPIRIT Table 1.

Table 1 Participants' timeline. Schedule of enrolment, interventions, and assessments

\begin{tabular}{|c|c|c|c|c|c|c|c|c|c|}
\hline \multirow[b]{3}{*}{ TIMEPOINT*** } & \multicolumn{9}{|c|}{ STUDY PERIOD } \\
\hline & \multicolumn{2}{|c|}{ Pre allocation } & \multirow{2}{*}{$\begin{array}{c}\text { Allocation } \\
0\end{array}$} & \multicolumn{6}{|c|}{ Post-allocation } \\
\hline & Enrollment & $\begin{array}{l}\text { Baseline } \\
t_{0}\end{array}$ & & $\begin{array}{c}t_{1 w} \\
\text { Week } 1\end{array}$ & $\begin{array}{c}t_{2 w} \\
\text { Week } 2\end{array}$ & $\begin{array}{c}t_{3 w} \\
\text { Week } 3\end{array}$ & $\begin{array}{c}t_{4 w} \\
\text { Week } 4\end{array}$ & $\begin{array}{c}t_{3 m} \\
\text { End of } \\
\text { 3rd } \\
\text { month } \\
\end{array}$ & $\begin{array}{c}t_{6 m} \\
\text { End of } \\
6 \text { th } \\
\text { month }\end{array}$ \\
\hline \multirow{4}{*}{$\begin{array}{l}\text { ENROLMENT: } \\
\text { Eligibility screen } \\
\text { Informed consent } \\
\text { Allocation }\end{array}$} & & & & & & & & & \\
\hline & $x$ & & & & & & & & \\
\hline & $x$ & & & & & & & & \\
\hline & & & $x$ & & & & & & \\
\hline \multicolumn{10}{|l|}{ INTERVENTIONS: } \\
\hline \multirow{2}{*}{ Intervention group } & \multicolumn{3}{|c|}{ Fascial Manipulation } & $x$ & $x$ & $x$ & $x$ & & \\
\hline & \multicolumn{3}{|c|}{$\begin{array}{l}\text { Home based unsupervised } \\
\text { Sequential Yoga Poses }\end{array}$} & \multicolumn{5}{|c|}{$\longmapsto$} & \\
\hline \multirow[t]{2}{*}{ Control Group } & \multicolumn{3}{|c|}{$\begin{array}{c}\text { Cervical and thoracic mobilisation, } \\
\text { Thoracic and cervicothoracic } \\
\text { manipulation }\end{array}$} & $\mathrm{X}$ & $x$ & $x$ & $x$ & & \\
\hline & \multicolumn{3}{|c|}{$\begin{array}{c}\text { Home based unsupervised } \\
\text { Therapeutic exercises }\end{array}$} & \multicolumn{5}{|c|}{$\mid$} & \\
\hline \multicolumn{10}{|l|}{ ASSESSMENTS: } \\
\hline \multicolumn{10}{|l|}{$\begin{array}{l}\text { Primary outcome } \\
\text { measure }\end{array}$} \\
\hline NPRS & & $x$ & & & $x$ & $x$ & $x$ & $x$ & $\mathrm{X}$ \\
\hline \multicolumn{10}{|l|}{$\begin{array}{l}\text { Secondary outcome } \\
\text { measures }\end{array}$} \\
\hline $\begin{array}{l}\text { Oculomotor control } \\
\text { [SPNT, NPC test] }\end{array}$ & & $x$ & & & & & $x$ & $x$ & \\
\hline PSFS & & $x$ & & & & & $x$ & $x$ & $x$ \\
\hline$F A B Q$ & & $x$ & & & & & & $x$ & $\mathrm{X}$ \\
\hline Myofascial stiffness & & $x$ & & & & & $x$ & $x$ & \\
\hline EEROM & & $x$ & & & $x$ & $x$ & $x$ & $x$ & \\
\hline
\end{tabular}

*Summary of measures to be collected [SPIRIT guidelines 2013]

NPRS numerical pain rating scale, PSFS patient-specific functional scale, FABQ fear avoidance behavior questionnaire, SPNT smooth pursuit neck torsion test, NPC near point convergence, EEROM elbow extension range of motion 


\section{Sample size}

The sample size is estimated based on the primary outcome NPRS. The threshold for MCID in MNP patients with and without UE symptoms is 2.2 and 1.5, respectively [51], whereas the MCID for NPRS in patients with chronic musculoskeletal pain is 1 [52]. Thus, MCID is considered as one in order to have a substantial sample size in this trial.

$$
n=\frac{2\left(Z_{1-\alpha / 2}+Z_{1-\beta}\right) \cdot \sigma^{2}[1+(m-1) \rho]}{m d^{2}}
$$

$d-\mathrm{MCID}=1$

$\mathrm{Z}_{1-\alpha / 2}=1.96$ at $\alpha=0.05$

$\mathrm{Z} 1-\beta=1.28$ at $90 \%$ power

$m=$ Number of time points/follow-ups $=5$

$\rho=$ Intraclass correlation $=0.4$

$$
n=\frac{2 \times(1.96+1.28)^{2} \times 2.5^{2} \times 2.2}{5 \times 1^{2}}=\mathbf{5 8}
$$

Accounting for dropout rate/non-response rate $N^{x}=N / 1$ - dropout rate; for $10 \%$ dropout rate Required sample size $=\mathbf{6 4}$ participants/group.

Total number of participants in the trial $=\mathbf{1 2 8}$

To detect a difference of one on the NPRS scale (pain intensity) between the groups assuming a standard deviation of 2.5 at a $5 \%$ level of significance and $90 \%$ power and $10 \%$ dropout, the minimum number of participants required in each group is $\mathbf{6 4}$.

\section{Recruitment}

All participants will be recruited from the Department of Orthopedics, Kasturba Hospital, Manipal. An orthopedician will conduct an initial assessment of the participants with sub-acute and chronic mechanical neck pain. Subjective and objective evaluations including the physical examination will be performed by the orthopedician. In addition, cervical X-rays of the participants with the clinical features of MNP will be done to rule out serious pathology of the cervical spine. The patients with MNP without any red flag symptoms for manual therapy will be recruited. Since the orthopedician is at the first level of recruitment principal investigator will keep him updated regarding the progress of the trial every week to achieve adequate recruitment of the participants.

\section{Recruitment status}

Anticipated date of enrollment of first participant - July 10, 2020.

\section{Methods: assignment of interventions Allocation}

Sequence generation Random assignment of participants to either control or the intervention group will be conducted at an allocation ratio of 1:1. The sequence will be computer-generated using $\mathrm{R}$ software, with two strata, which include group 1: age (18-30) and group 2: age (31-45). Sixteen blocks of 10 people (5 in the control group and 5 in the intervention group) will be used.

Allocation concealment mechanism Neither the investigator nor the outcome assessors will involve in the enrolment or allocation process. The person who will not be involved in the trial will make the randomization schedule and pack the sequentially numbered, opaque, and sealed envelopes, which will be used to randomize the participants.

Implementation The participants who fulfill the inclusion criteria and give consent for participating in the trial will be randomized. The member not involved in the trial will do randomization. Randomization numbers and the therapy group's corresponding code will be available within the closed envelopes. Staff responsible for recruitment will not receive any information about the allocation of groups.

Table 2 Summary of reporting outcome measures

\begin{tabular}{lr}
\hline Variables/outcomes & Methods of analysis \\
\hline Primary outcome measure & Repeated measures ANOVA \\
NPRS (change of pain score during last week) $\left[\Delta t_{o} \rightarrow t_{3 m} \rightarrow t_{6 m}\right]$ & Repeated measures ANOVA \\
Secondary outcome measures & \\
PSFS (change of functions score) $\left[\Delta t_{0}-t_{4}\right],\left[\Delta t_{o} \rightarrow t_{3 m} \rightarrow t_{6 m}\right]$ & \\
FABQ $\left[\Delta t_{o} \rightarrow t_{3 m} \rightarrow t_{6 m}\right]$ & \\
EEROM $\left[\Delta t_{o} \rightarrow t_{3 m}\right]$ & \\
Myofascial stiffness $\left[\Delta t_{o} \rightarrow t_{3 m}\right]$ &
\end{tabular}

NPRS numerical pain rating scale, PSFS patient-specific functional scale, FABQ fear-avoidance behavior questionnaire, EEROM elbow extension range of motion $\boldsymbol{t}_{\boldsymbol{o}}$ baseline, $\boldsymbol{t}_{\mathbf{1}}$ week $1, \boldsymbol{t}_{\mathbf{2}}$ week $2, \boldsymbol{t}_{\mathbf{3}}$ week $3, \boldsymbol{t}_{\mathbf{4}}$ week $4, \boldsymbol{t}_{\mathbf{3} \boldsymbol{m}} 3$ months following the 1 st treatment session, $\boldsymbol{t}_{\boldsymbol{6}} 6$ months following the 1 st treatment session 
Table 3 Outcomes (mean, SD)

\begin{tabular}{|c|c|c|c|c|c|c|c|c|c|c|c|c|}
\hline \multirow[t]{2}{*}{ Outcomes } & \multicolumn{2}{|c|}{ Baseline/before 1st TS } & \multicolumn{2}{|c|}{ Before 2nd TS } & \multicolumn{2}{|c|}{ Before 3rd TS } & \multicolumn{2}{|c|}{ Before 4th TS } & \multicolumn{2}{|c|}{ 3rd month follow-up } & \multicolumn{2}{|c|}{ 6th month follow-up } \\
\hline & $\overline{\text { IG }}$ & CG & $\overline{\text { IG }}$ & CG & $\overline{I G}$ & CG & $\overline{\text { IG }}$ & CG & $\overline{\text { IG }}$ & CG & $\overline{\text { IG }}$ & CG \\
\hline NPRS & $x$ & $x$ & $x$ & $x$ & $x$ & $x$ & $x$ & $x$ & $x$ & $x$ & $x$ & $x$ \\
\hline EEROM & $x$ & $x$ & $x$ & $x$ & $x$ & $x$ & $x$ & $x$ & $x$ & $x$ & & \\
\hline PSFS & $x$ & $x$ & & & & & $x$ & $x$ & $x$ & $x$ & $x$ & $x$ \\
\hline Oculomotor functions & $x$ & $x$ & & & & & $x$ & $x$ & $x$ & $x$ & & \\
\hline Myofascial stiffness & $x$ & $x$ & & & & & $x$ & $x$ & $x$ & $x$ & & \\
\hline FABQ & $x$ & $x$ & & & & & & & $x$ & $x$ & $x$ & $x$ \\
\hline
\end{tabular}

TS treatment session, IG intervention group, CG control group, NPRS numerical pain rating scale, PSFS patient-specific functional scale, FABQ fear avoidance behavior questionnaire, EEROM elbow extension range of motion

Blinding The intent of the study, i.e., a comparison between the two different treatment regimens, will be explained to the patients, and the outcome assessor will be blinded.

Emergency unblinding As the interventions can be modified based on the patient's pain threshold and response, there is less likelihood of circumstances where unblinding will be required. If there is any adverse effect, the participants will be referred back to the orthopedician for further evaluation. The principal investigator after discussing with the orthopedician may modify or discontinue the treatment protocol based on his suggestion.

\section{Methods: data collection, management, and analysis Data collection methods}

Data collection After obtaining written consent, the investigator will assess and evaluate the patients. The same outcome assessors will perform all post-allocation assessments.

Retention The investigator will maintain periodic communication by sending text message reminders for all scheduled treatment as well as follow-up appointments. The investigator will also maintain consistency in implementation and flexible with the study schedule. The participants will be offered to reschedule their appointment within the allotted time interval between the sessions, in

Table 4 Between-group difference in change of scores

\begin{tabular}{|c|c|c|c|c|c|c|c|c|c|c|c|c|c|c|c|}
\hline \multirow{3}{*}{ Outcome } & \multicolumn{15}{|c|}{ Change in scores between the treatment sessions and follow-up } \\
\hline & \multicolumn{3}{|c|}{$\Delta t_{0}-t_{2}$} & \multicolumn{3}{|c|}{$\Delta t_{2}-t_{3}$} & \multicolumn{3}{|c|}{$\Delta t_{3}-t_{4}$} & \multicolumn{3}{|c|}{$\Delta t_{4}-t_{3 m}$} & \multicolumn{3}{|c|}{$\Delta t_{3 m}-t_{6 m}$} \\
\hline & IG & CG & $\begin{array}{l}\text { Diff } \\
\text { (IG \& CG) }\end{array}$ & IG & CG & $\begin{array}{l}\text { Diff } \\
(I G \& C G)\end{array}$ & IG & CG & $\begin{array}{l}\text { Diff } \\
(\text { IG \& CG) }\end{array}$ & IG & CG & $\begin{array}{l}\text { Diff } \\
(I G \& C G)\end{array}$ & IG & CG & $\begin{array}{l}\text { Diff } \\
\text { (IG \& CG) }\end{array}$ \\
\hline
\end{tabular}

NPRS

EEROM

Outcome measures Change in scores between treatment sessions and follow-up.

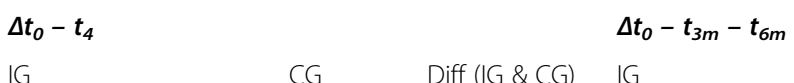

IG $\quad$ CG Diff (IG\&CG) IG Diff (IG \& CG)

PSFS

FABQ

Outcome measures Change in scores between treatment sessions and follow - up.

$$
\begin{aligned}
& \Delta t_{o}-t_{4} \quad \Delta t_{4}-t_{3 m} \\
& \text { IG CG } \quad \text { Diff } \quad I G \quad C G \quad \text { Diff }
\end{aligned}
$$


Table 5 Appraisal of FaCe-Man trial

\begin{tabular}{ll}
\hline Features & FaCe-Man trial \\
\hline Problem base & Considering the prevalence and chronicity of MNP *, it needs to be addressed. \\
Context placement & Systematic assessment of prior evidence reveals a research gap \\
Information gain & Large enough to be informative \\
Pragmatism & Pragmatic approach to reflect the real life \\
Patient-centeredness & Patient centric \\
Value for money & Focuses on larger group of population with MNP \\
Feasibility & Feasible \\
Transparency & Method, data, and analyses will be verifiable and unbiased \\
\hline
\end{tabular}

*MNP Mechanical Neck Pain

Adapted from loannidis JPA (2016). Why most clinical research is not useful. PLOS Medicine 13 [6]

case of inability to attend their scheduled treatment session and follow-up assessment.

\section{Data management}

The patient will fill all the patient-reported questionnaires; the therapist/outcome assessor will fill the outcome measures in paper formats, provided separately. Consequently, all data will be entered electronically, including the Google forms data (online as well as paperbased) will be saved on a secured drive at the study setting. All the original files of the participants will also be stored in a secure and accessible place.

\section{Statistical methods}

For all the continuous primary and secondary outcomes listed in Table 2, where repeated measurements are to be taken, repeated measures ANOVA will be used. The Student's $t$ test will compare the intervention group (IG) and the control group (CG) during interim assessments. The difference in means will be used for the analysis of continuous variables. All statistical tests will be carried out at a 5\% (two-sided) significance level. All analyses will be carried out using the $\mathrm{R}$ software, which is opensource software. Patients will be stratified into group 1 ages $18-30$ and group 2 ages $31-45$. Subgroup analysis will be done based on these groups.

The mean scores and corresponding 95\% CIs will be reported for all the outcomes to be measured between different time points $\left(\Delta \mathrm{t}_{0} \rightarrow \mathrm{t}_{6 \mathrm{~m}}\right)$ as shown in Table 3 . The difference in all outcomes between the interventional and control groups will be reported as shown in Table 4.

Statistical methods-analysis population and missing data Regardless of the protocol adherence, all key analyses will be conducted as intention-to-treat (ITT) analyses, including all randomized participants. If there is any missing outcome datum, multiple imputation methods will be done, so that a complete dataset will be available for the ITT analysis.

Table 6 FINER criteria for a good research question

\begin{tabular}{ll}
\hline FINER criteria & FaCe-Man trial \\
\hline $\begin{array}{l}\text { Feasible } \\
\text { Adequate number: } \\
\quad \text { Subject } \\
\text { Expertise }\end{array}$ & $\uparrow$ MNP* patients \\
Affordable & Multi-disciplinary trial \\
Manageable & Yes \\
Interesting & It can be completed within the allotted time \\
Novel & Investigator/research community/clinicians \\
Ethical & Myofascial continuum and force transmission \\
& Fascia directed approach \\
Research & Low to moderate risk \\
& Clearance from Institutional Research and Ethics Committee \\
\hline
\end{tabular}

*MNP Mechanical Neck Pain

Adapted from Hulley et al. Designing clinical research, 3rd ed. 


\section{Methods: monitoring \\ Data monitoring}

Data monitoring committee No separate Data Monitoring Committee (DMC) will be formed, as the Institutional Research Committee members will perform the roles of DMC. No formal stopping guidelines and corresponding interim analysis are planned.

Harms The primary investigator will record the treatment-related adverse events, including any abnormal signs and acute exacerbations of symptoms during the assessment or treatment sessions. In case of the requirement of medical evaluation, the participants will be referred to the respective medical department.

Auditing The Doctoral Advisory Committee (DAC) members will conduct regular audits.

\section{Discussion}

This FaCe-Man trial will investigate the effectiveness of the fascia-directed treatment approach compared to usual care in patients with MNP. If found useful in improving patient-reported functions and pain, the intervention can be used as an effective strategy in managing MNP and their associated plethora of symptoms. The research question appears to fulfill the FINER criteria, as described in Table $5[65,66]$. As MNP contributes significantly to global disability and substantial societal burden, the "problem base" is large enough, which needs to be addressed. Also, concerning "the context placement," the prior evidence shows a lack of knowledge in terms of the DCF continuum and their involvement in causing musculoskeletal pain. It is also essential to study the effectiveness of fascia directed approach addressing the impaired myofascial continuum of the UQR. The FaCeMan trial may contribute to fill this research gap.

This study is designed for multiple follow-ups at different time points, which would improve the quality of the trial. The pragmatic approach will be followed in this trial, thus reflecting the clinical practice situation. Moreover, the patient-reported outcomes such as pain and patient-specific functions, which are the usual symptoms associated with neck pain, would also improve the trial's patient-centeredness.

Using SPIRIT and TIDieR guidelines will improve the transparency of the study methods and analysis, thus enhancing the relevance of the trial and their results.

Appraisal of the FaCe-Man trial and the FINER Criteria for a good research question is shown in Tables 5 and 6 .

\section{Trial status}

Issue date: October 8, 2019
Protocol amendment number: Amendment 01: modified on January 8, 2020 with changes in inclusion age criteria, sample size, and follow-up

\begin{tabular}{lll}
\hline & Initial & (Amendment 01) modifications \\
\hline $\begin{array}{l}\text { Participant's } \\
\text { age group }\end{array}$ & $\begin{array}{l}\text { Age group: 18-65 } \\
\text { years }\end{array}$ & Age group: 18-45 years. \\
Sample size & $\begin{array}{l}\text { Total number of } \\
\text { participants= 120 } \\
\text { (60 participants in } \\
\text { each group) }\end{array}$ & $\begin{array}{l}\text { Total number of participants= } 126 \\
\text { (58 participants in each group) }\end{array}$ \\
Procedure & 3-month follow-up & $\begin{array}{l}\text { Included 6-month follow-up fol- } \\
\text { lowing the first intervention }\end{array}$ \\
\hline
\end{tabular}

Date of first recruitment: July 08, 2020

Tentative date of final recruitment: August 10, 2022

\begin{abstract}
Abbreviations
FaCe-Man trial: Fascia cervicalis manipulation trial; MNP: Mechanical neck pain; PAM: Patho-anatomical model; TBC: Treatment-based classification; DF: Deep fascia; UQR: Upper quarter region; EEROM: Elbow extension ROM; COR: Cervico-ocular reflex; DCF: Deep cervical fascia; MC: Myofascial continuum; FM: Fascial manipulation; CC: Centre of coordination; CF: Centre of fusion; IG: Intervention group; UCG: Usual care group; NPRS: Numeric pain rating scale; PROM: Patient-reported outcome measures; SYP: Sequential yoga poses; CM: Cervical mobilization; TM: Thoracic manipulation; PSFS: Patient-specific functional scale; SPNT: Smooth pursuit neck torsion; FABQ: Fear-avoidance belief questionnaire; ULNT1: Upper Limb Neurodynamics Test
\end{abstract}

\section{Supplementary Information}

The online version contains supplementary material available at https://doi. org/10.1186/s13063-021-05533-w.

Additional file 1. SPIRIT (Standard Protocol Items: Recommendations for Interventional Trials) checklists (2013).

Additional file $\mathbf{2}$ TIDieR Control group (Usual care group).

Additional file 3. TIDieR Intervention group.

Additional file 4. Therapeutic exercises - Information leaflet.

Additional file 5. Yoga poses - Information leaflet.

\section{Acknowledgements}

The authors wish to acknowledge Mrs. Ashwini for her assistance in editing this manuscript.

Consent to participate

The principal investigator will obtain informed consent from the participants.

Protocol amendments

If there are any modifications in the protocol, amendments will be communicated with the IEC.

\section{Confidentiality}

All information about the participants, including the paper forms as well as the electronic data, will be securely stored at the study site. Access to these data will be limited. Information about the study will not be released without the participant's prior permission.

Ancillary and post-trial care

No ancillary or post-trial care will be provided to the participants.

Dissemination policy

Communicating trial result: 
The details of the interventions will be given to the participants if requested, so that trained therapists can replicate the treatment.

Authorship eligibility:

Committee on Publication Ethics (COPE) guidelines on good publication practice will be followed.

\section{Authors' contributions}

PR is the principal investigator. SB and CF are the co-investigators. PR, SB, and $C F$ are responsible for the study conception, design, and implementation. AP, CF, RG, RS, and FD have contributed to the conceptualization and design of the study along with PR. RG and AP assisted PR in drafting the background and methods sections of the manuscript. The authors have given the final approval of the manuscript to be submitted for publication.

\section{Funding}

This research did not receive any specific grants from funding agencies in the public, commercial, or not-for-profit sectors.

\section{Availability of data and materials}

Upon publication of the study results, the corresponding author will provide data if the scientific journal requires a full dataset. There are no contractual agreements that limit the dataset access for the investigator.

\section{Declarations}

\section{Ethics approval and consent to participate}

Kasturba Medical College and Kasturba Hospital Institutional Ethics Committee (Registration No. ECR/146/Inst/KA/2013/RR-19), Manipal Academy of Higher Education, Manipal, Karnataka, India, have approved the study. Approval ID is IEC: 790/2019. Registration date.

\section{Consent for publication}

Regarding the publication of images, written informed consent was obtained from the persons whose images were portrayed on the intervention information leaflets.

\section{Competing interests}

The authors declare that there are no financial or other competing interests.

\section{Author details}

${ }^{1}$ Interdisciplinary Centre for Craniofacial and Orofacial pain Research, Department of Exercise and Sports Science, Manipal College of Health Professions, Manipal Academy of Higher Education, Manipal, Karnataka 576 104, India. ${ }^{2}$ Department of Orthopedics, Kasturba Medical College, Manipal Academy of Higher Education, Manipal, India. ${ }^{3}$ Department of Physical Therapy, Occupational Therapy, Rehabilitation and Physical Medicine, Universidad Rey Juan Carlos, Madrid, Spain. ${ }^{4}$ Department of Physiotherapy, Manipal College of Health Professions, Manipal Academy of Higher Education, Manipal, India. ${ }^{5}$ Department of Exercise and Sports Sciences, Manipal College of Health Professions, Manipal Academy of Higher Education, Manipal, India. ${ }^{6}$ Department of Data Science, Manipal Academy of Higher Education, Manipal, India.

\section{Received: 11 November 2020 Accepted: 11 August 2021}

\section{Published online: 28 August 2021}

\section{References}

1. Muñoz-García D, Gil-Martínez A, López-López A, Lopez-de-Uralde-Villanueva I, La Touche R, Fernández-Carnero J. Chronic Neck Pain and CervicoCraniofacial Pain Patients Express Similar Levels of Neck Pain-Related Disability, Pain Catastrophizing, and Cervical Range of Motion. Pain Res Treat. 2016:7296032. https://doi.org/10.1155/2016/7296032. Epub 2016 Mar 29. PMID: 27119020; PMCID: PMC4828545.

2. Guzman J, Hurwitz EL, Carroll LJ, Haldeman S, Cote P, Carragee EJ, et al. A new conceptual model of neck pain: linking onset, course, and care Bone and Joint Decade 2000-2010 Task Force on Neck Pain and Its Associated Disorders. Spine. 2008;33(4 Suppl):S14-23. https://doi.org/10.1097/BRS.0b013 e3181643efb.

3. Fernández-de-las-Peñas C, Cleland J, Huijbregts P. Neck and arm pain syndromes. Evidence-informed screening, diagnosis, and management. 1st ed. Churchill Livingstone: Elsevier; 2011.
4. Yeun YR, Han SJ. Factors associated with neck/shoulder pain in young adults. Biomed Res. 2017;28(16):7117-21.

5. Ayoub LJ, Seminowicz DA, Moayedi M. A meta-analytic study of experimental and chronic orofacial pain excluding headache disorders. Neurolmage Clin. 2018;20:901-12. https://doi.org/10.1016/j.nicl.2018.09.018.

6. Gross A, Langevin P, Burnie SJ, Bedard-Brochu MS, Empey B, Dugas E, et al. Manipulation and mobilisation for neck pain contrasted against an inactive control or another active treatment. Cochrane Database Syst Rev. 2015;9: CD004249.

7. Cleland JA, Childs JD, Fritz JM, Whitman JM, Eberhart SL. Development of a clinical prediction rule for guiding treatment of a subgroup of patients with neck pain: use of thoracic spine manipulation, exercise, and patient education. Phys Ther. 2007;87(1):9-23. https://doi.org/10.2522/ptj.20060155.

8. Gross A, Kay TM, Paquin JP, Blanchette S, Lalonde P, Christie T, Dupont G, Graham N, Burnie SJ, Gelley G, Goldsmith CH, Forget M, Hoving JL, Brønfort G, Santaguida PL; Cervical Overview Group. Exercises for mechanical neck disorders. Cochrane Database Syst Rev. 2015;1:CD004250. https://doi.org/1 0.1002/14651858.CD004250.pub5. PMID: 25629215.

9. Kelly J, Ritchie C, Sterling M. Clinical prediction rules for prognosis and treatment prescription in neck pain: a systematic review. Musculoskelet Sci Pract. 2017;27:155-64. https://doi.org/10.1016/j.math.2016.10.066.

10. Allison G, Nagy BM, Hall T. A randomized clinical trial of manual therapy for cervicobrachial pain syndrome - a pilot study; 2002. p. 95-102.

11. Lopez-de-Uralde-Villanueva I, Beltran-Alacreu H, Fernandez-Carnero J, GilMartınez A, La Touche R. Differences in neural mechanosensitivity between patients with chronic nonspecific neck pain with and without neuropathic features. A descriptive cross-sectional study. Pain Med. 2016;17(1):136-48. https://doi.org/10.1111/pme.12856.

12. Gangavelli R, Nair NS, Bhat AK, Solomon JM. Cervicobrachial pain - how often is it neurogenic? J Clin Diagn Res. 2016;10(3):YC14-6. https://doi.org/1 0.7860/JCDR/2016/16456.7492

13. Costello M, Puentedura E, Cleland J, Ciccone CD. The immediate effects of soft tissue mobilization versus therapeutic ultrasound for patients with neck and arm pain with evidence of neural mechanosensitivity: a randomized clinical trial. J Man Manipulative Ther. 2016;24(3):128-40. https://doi.org/1 $0.1179 / 2042618614$ Y.0000000083.

14. Butler DS. Mobilisation of the nervous system. 1st ed. Melbourne: Churchill Livingstone; 1991.

15. Shaclock MO. Clinical Neurodynamics. A new system of musculoskeletal treatment. 1st ed. Elsevier Butterworth-Heinemann; 2005.

16. Wilke J, Krause F. Myofascial chains of the upper limb: A systematic review of anatomical studies. Clin Anat. 2019;32(7):934-40. https://doi.org/10.1002/ ca.23424. Epub 2019 Jul 2. PMID: 31226229.

17. Raja PG, Fernandes S, Cruz AM, Prabhu A. The plausible role of deep cervical fascia and its continuum in chronic craniofacial and cervicobrachial pain. A case report. Heliyon. 2020;6:e04560.

18. Purslow PP. Muscle fascia and force transmission. J Bodyw Mov Ther. 2010; 14(4):411-7. https://doi.org/10.1016/j.jbmt.2010.01.005.

19. Schleip R, Findley T, Chaitow L, Huijing P. The tensional network of the human body. 1st ed. Churchill Livingstone, Elsevier; 2012.

20. Stecco C. Functional Atlas of the human fascial system. 1st ed. Churchill Livingstone: Elsevier; 2015.

21. Bordoni B, Zanier E. Clinical and symptomatological reflections: the fascial system. J Multidiscip Healthc. 2014;7:401-11. https://doi.org/10.2147/JMDH.S68308.

22. De Vries J, Ischebeck BK, Voogt LP, Janssen M, Frens MA, Kleinrensink GJ, et al. Cervico-ocular reflex is increased in people with nonspecific neck pain. Phys Ther. 2016;96(8):1190-5. https://doi.org/10.2522/ptj.20150211.

23. Monaco A, Cattaneo R, Spadaro A, D'Andrea P, Marzo G, Gatto R. Ocular correction effects on EMG activity of stomatognathic muscles in children with functional mandibular lateral- deviation: a case-control study. Eur J Pediatr Dent. 2006:7(2):81-8.

24. Monaco A, Cattaneo R, Spadaro A, Giannoni M, Di Martino S, Gatto R. Visual input effect on EMG activity of masticatory and postural muscles in healthy and in myopic children. Eur J Paediatr Dent. 2006;7(1):18-22.

25. Treleaven J, Jull G, LowChoy N. The relationship of cervical joint position error to balance and eye movement disturbances in persistent whiplash. Man Ther. 2006;11(2):99-106. https://doi.org/10.1016/j.math.2005.04.003.

26. Treleaven J, Treleaven J. Sensorimotor disturbances in neck disorders affecting postural stability, head and eye movement control--part 2: case studies. Man Ther. 2008;13(3):266-75. https://doi.org/10.1016/j.math.2007.11. 002. 
27. Treleaven J. Dizziness, unsteadiness, visual disturbances, and sensorimotor control in traumatic neck pain. J Orthop Sports Phys Ther. 2017:47(7):492502. https://doi.org/10.2519/jospt.2017.7052.

28. Stecco L. Fascial Manipulation for Musculoskeletal Pain: Piccin; 2004.

29. Wilke J, Schleip R, Yucesoy CA, Banzer W. Not merely a protective packing organ? A review of fascia and its force transmission capacity. J Appl Physiol (Bethesda, Md: 1985). 2018;124(1):234-44.

30. Schleip RKW, Zorn A. Biomechanical properties of fascial tissues and their role as pain generators. J Musculoskelet Pain. 2010;18(4):393-6. https://doi. org/10.3109/10582452.2010.502628.

31. Mathew NP, Raja GP, Davis F. Effect of Fascial manipulation on glenohumeral internal rotation deficit in overhead athletes - a randomized controlled trial. Muscles Ligaments Tendons J. 2020;10(1):17-23. https://doi. org/10.32098/mltj.01.2020.03.

32. Alison J. Yoga: fascia, form, and functional movement. 1st ed. UK: Handspring; 2015.

33. Scaravelli V, lyengar BKS, Howard R. Awakening the spine: yoga for health, vitality, and energy. Harper Collins; 2012.

34. Myers TW. Anatomy Trains: Myofascial Merdians for Manual and Movement Therapists. 3rd ed: Churchill Livingstone: Elsevier; 2014.

35. Cleland JA, Childs JD, Whitman JM. Psychometric properties of the Neck Disability Index and Numeric Pain Rating Scale in patients with mechanical neck pain. Arch Phys Med Rehabil. 2008;89(1):69-74. https://doi.org/10.1016/ j.apmr.2007.08.126.

36. Chan A-W, Tetzlaff JM, Altman DG, Laupacis A, Gøtzsche PC, Krleža-Jerić K, et al. SPIRIT 2013 statement: defining standard protocol items for clinical trials. Ann Intern Med. 2013;158(3):200-7. https://doi.org/10.7326/0003-481 9-158-3-201302050-00583.

37. Bandholm T, Christensen R, Thorborg K, Treweek S, Henriksen M. Preparing for what the reporting checklists will not tell you: the PREPARE Trial guide for planning clinical research to avoid research waste. Br J Sports Med. 2017; 51(20):1494-501. https://doi.org/10.1136/bjsports-2017-097527.

38. Hoffmann TC, Glasziou PP, Boutron I, Milne R, Perera R, Moher D, et al. Better reporting of interventions: template for intervention description and replication (TIDieR) checklist and guide. BMJ. 2014;348(mar07 3):g1687. https://doi.org/10.1136/bmj.g1687.

39. Gibbons P, Tehan P. Manipulation of the spine, thorax, and pelvis. 4th ed. Elsevier; 2016.

40. Grieve GP. Common vertebral joint problems. 2nd ed. London: Churchill Livingstone, Elsevier; 1988.

41. Basmajian. Rational manual therapies. 1st ed. Baltimore: Williams \& Wilkins; 1993.

42. Maitland GD, English K. Maitland's vertebral manipulation-Volume 1. 7th ed. Elsevier; 2005

43. Posadzki P, Ernst E. Spinal manipulation: an update of a systematic review of systematic reviews. N Z Med J. 2011;124(1340):55-71.

44. Evans DW, Breen AC. A biomechanical model for mechanically efficient cavitation production during spinal manipulation: prethrust position and the neutral zone. J Manipulative Physiol Ther. 2006;29(1):72-82. https://doi. org/10.1016/j.jmpt.2005.11.011.

45. Boyling JD, Jull GA. Grieves modern manual therapy. The vertebral column. 3rd ed: Elsevier; 2004.

46. Cotti A, Del Corso M, Diana R, Cornale L, Sudanese A, Stecco A, Branchini M. Inter and Intra Operator Reliability of Motor and Palpation Evaluation in Fascial Manipulation in individuals with coxarthrosis. J Man Manip Ther. 2020;28(4):236-45. https://doi.org/10.1080/10669817.2019.1683675. Epub 2019 Oct 31. PMID: 31668142.

47. Stecco A, Macchi V, Stecco C, Porzionato A, Ann Day J, Delmas V, et al. Anatomical study of myofascial continuity in the anterior region of the upper limb. J Bodyw Mov Ther. 2009;13(1):53-62. https://doi.org/10.1016/j. jbmt.2007.04.009.

48. Day JA, Stecco C, Stecco A. Application of fascial manipulation technique in chronic shoulder pain-anatomical basis and clinical implications. J Bodyw Mov Ther. 2009;13(2):128-35. https://doi.org/10.1016/j.jbmt.2008.04.044.

49. Argent R, Daly A, Caulfield B. Patients involement with home-based exercise programs: can connected health interventions influence adherence? 2018. p. e47.

50. Bollen JC, Dean SG, Siegert RJ, Howe TE, Goodwin VA. A systematic review of measures of self-reported adherence to unsupervised home-based rehabilitation exercise programmes, and their psychometric properties. BMJ Open. 2014;4(6):e005044. https://doi.org/10.1136/bmjopen-2014-005044.
51. Young IA, Dunning J, Butts R, Cleland JA, Fernandez-de-Las-Penas C. Psychometric properties of the Numeric Pain Rating Scale and Neck Disability Index in patients with cervicogenic headache. Cephalalgia. 2019; 39(1):44-51. https://doi.org/10.1177/0333102418772584.

52. Salaffi F, Stancati A, Silvestri CA, Ciapetti A, Grassi W. Minimal clinically important changes in chronic musculoskeletal pain intensity measured on a numerical rating scale. Eur J Pain. 2004;8(4):283-91. https://doi.org/10.1016/j. ejpain.2003.09.004 PMID: 15207508.

53. Hefford C, Abbott JH, Arnold R, Baxter GD. The patient-specific functional scale: validity, reliability, and responsiveness in patients with upper extremity musculoskeletal problems. J Orthop Sports Phys Ther. 2012;42(2): 56-65. https://doi.org/10.2519/jospt.2012.3953.

54. Tjell C, Rosenhall U. Smooth pursuit neck torsion test: a specific test for cervical dizziness. Am J Otol. 1998;19(1):76-81.

55. Treleaven J. Sensorimotor disturbances in neck disorders affecting postural stability, head and eye movement control. Man Ther. 2008;13(1):2-11. https://doi.org/10.1016/j.math.2007.06.003.

56. Daly L, Giffard P, Thomas L, Treleaven J. Validity of clinical measures of smooth pursuit eye movement control in patients with idiopathic neck pain. Musculoskelet Sci Pract. 2018;33:18-23. https://doi.org/10.1016/j. msksp.2017.10.007.

57. Giffard P, Daly L, Treleaven J. Influence of neck torsion on near point convergence in subjects with idiopathic neck pain. Musculoskelet Sci Pract. 2017;32:51-6. https://doi.org/10.1016/j.msksp.2017.08.010.

58. George SZ, Stryker SE. Fear-avoidance beliefs and clinical outcomes for patients seeking outpatient physical therapy for musculoskeletal pain conditions. J Orthop Sports Phys Ther. 2011;41(4):249-59. https://doi.org/1 0.2519/jospt.2011.3488

59. Lee KC, Chiu TT, Lam TH. The role of fear-avoidance beliefs in patients with neck pain: relationships with current and future disability and work capacity. Clin Rehabil. 2007;21(9):812-21. https://doi.org/10.1177/0269215507077800.

60. Fritz JM, George SZ, Delitto A. The role of fear-avoidance beliefs in acute low back pain: relationships with current and future disability and work status. Pain. 2001;94(1):7-15. https://doi.org/10.1016/S0304-3959(01)00333-5.

61. Lee KC, Chiu TT, Lam TH. Psychometric properties of the Fear-Avoidance Beliefs Questionnaire in patients with neck pain. Clin Rehabil. 2006;20(10): 909-20. https://doi.org/10.1177/026921550506072186.

62. Marusiak J, Jarocka E, Jaskolska A, Jaskolski A. Influence of the number of records on the reliability of myotonometric measurements of muscle stiffness at rest and contraction. Acta Bioeng Biomech. 2018;20(4):123-31.

63. Bailey LSD, Warner MB. Parameters representing muscle tone, elasticity, and stiffness of biceps brachii in healthy older males: symmetry and withinsession reliability using the MyotonPRO. J Neurol Disord. 2013;1:116.

64. Likhite AS, Balthillaya GM, Prabhu A, Gangavelli R. Effect of upper limb neural mobilization on vibration threshold and handgrip strength in asymptomatic individuals: a randomized controlled trial; 2017. p. YC05-YC8.

65. JPA L. Why most clinical research is not useful. PLoS Med. 2016;13(6):1-1.

66. Ioannidis JP. The mass production of redundant, misleading, and conflicted systematic reviews and meta-analyses. Milbank Q. 2016;94(3):485-514. https://doi.org/10.1111/1468-0009.12210.

\section{Publisher's Note}

Springer Nature remains neutral with regard to jurisdictional claims in published maps and institutional affiliations.

Ready to submit your research? Choose BMC and benefit from:

- fast, convenient online submission

- thorough peer review by experienced researchers in your field

- rapid publication on acceptance

- support for research data, including large and complex data types

- gold Open Access which fosters wider collaboration and increased citations

- maximum visibility for your research: over $100 \mathrm{M}$ website views per year

At $\mathrm{BMC}$, research is always in progress.

Learn more biomedcentral.com/submissions 